\title{
Liquid Desiccant Vapor Separation Reduces the Energy Requirements of Atmospheric Moisture Harvesting Systems
}

\author{
Supplementary Information
}

Ben Gido, Eran Friedler, David M. Broday

\section{Content}

- Operational parameters of the simulated LDS-system (Table S1) that fit all the examined ambient air thermodynamic conditions, found by a trial and error search. As such, these parameters are identical throughout all the simulations.

- Detailed explanation of the constrained optimization process of the LDS-system model, with visual example for specific air conditions (Fig 1S).

- Detailed account of the parasitic losses (Table 2S) and visual presentation of a sensitivity analysis showing how will the specific energy requirement $(\mathrm{kWh} / \mathrm{l})$ change $(\%)$ if the parasitic losses are larger by $50 \%$ than estimated in the main text.

5 pages, 2 Tables, 2 Figures.

\section{LDS sub-system model}

Reasonable model parameters that guarantied convergence of the ABSIM simulations were determined by a trial-and-error search and are detailed in Table 1S. These parameters were used as constraints during the optimization process. The system operation was investigated under different objectives, including maximum water production for a given temperature of the hot water stream to the desorber and of the cold water stream to the condenser.

As an example, Figure 1S depicts a result of ABSIM runs in search of optimal operation for ambient air temperature of $20{ }^{\circ} \mathrm{C}$ and a mixing ratio of $0.008 \mathrm{~kg}_{\mathrm{w}} / \mathrm{kg}_{\mathrm{a}}(\sim 55 \% \mathrm{RH})$. The matrix of all the combinations of the condenser and desorber temperatures for which the ABSIM converged (i.e. which enable the LDS-AMH process depicted in Fig. 1 in the manuscript) is 
shown in Figure 1Sa. Figure 1Sb shows the matrix of the condenser and desorber temperatures that enable operation under the above conditions without crystallization of the desiccant solution at any state points in Fig. 1. The freshwater production rate at every permissible configuration (i.e. that was found to be within the ABSIM convergence region and the non-crystallization region) is shown in Figure 1Sc, together with the optimal working point for the specified ambient conditions.

Table 1S. LDS sub-system operation parameters (obtained via a trial-and-error ABSIM runs). $U$ is the specific heat transfer coefficient, $A$ is the heat transfer area, and the product $U A$ is the overall heat transfer coefficient.

Flow rates

Desiccant stream, absorption cycle

$\mathrm{kg} / \mathrm{s}$

0.15

Hot stream

$\mathrm{kg} / \mathrm{s}$

0.50

Cold stream

$\mathrm{kg} / \mathrm{s}$

0.50

Air flow through the absorber

$\mathrm{kg} / \mathrm{s}$

1.0

Heat transfer parameters

Liquid-liquid heat exchanger $U A$

$\mathrm{kW} /{ }^{0} \mathrm{C}$

0.2

Desorber heat exchanger efficiency

$\%$

47.0

Condenser heat exchanger efficiency

$\%$

76.5

Mass (vapor) transfer coefficients

$\begin{array}{lll}\text { LDS solution } & \mathrm{kg} / \mathrm{s} & 0.6 \\ \text { Air } & \mathrm{kg} / \mathrm{s} & 0.6\end{array}$



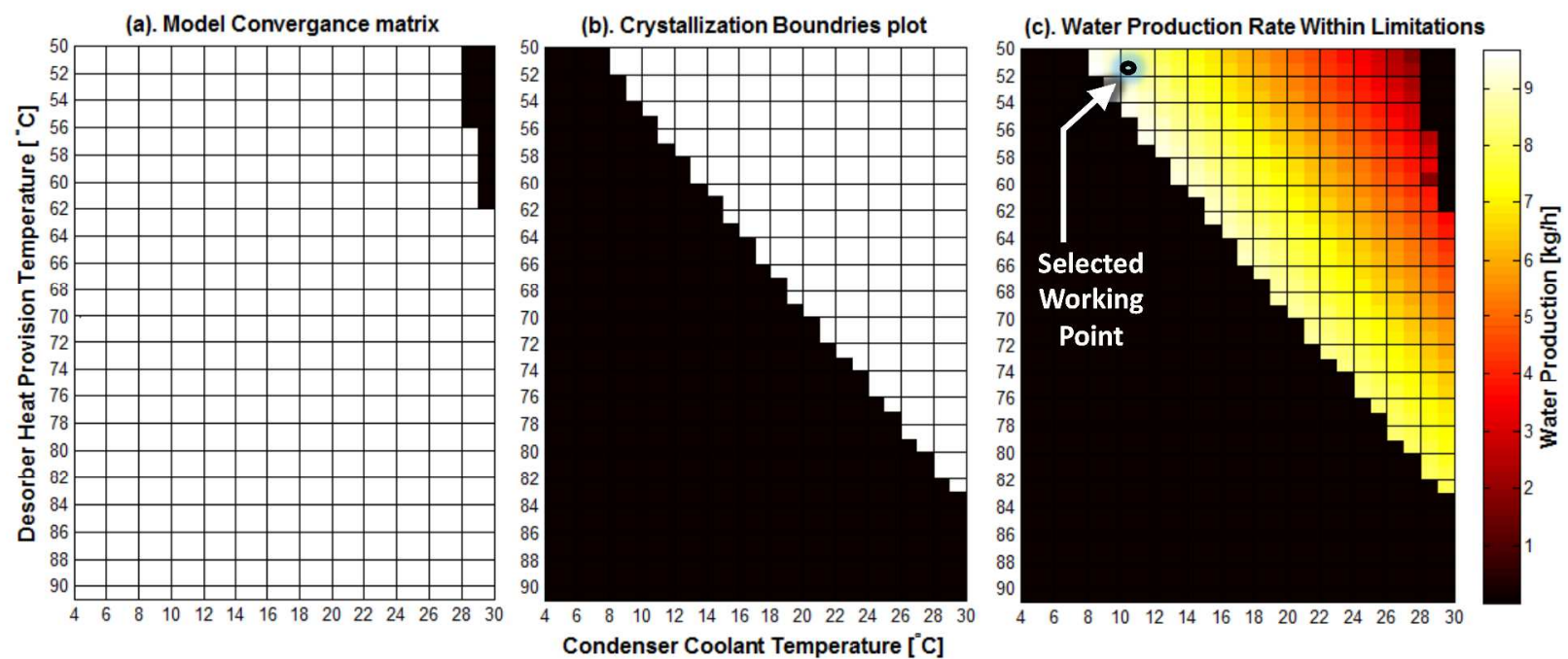

Figure 1S. Example of LDS working point determination for ambient conditions of $20{ }^{0} \mathrm{C}$ and 55\% RH. (a) Model convergence matrix, (b) crystallization boundary, and (c) water production rate. The optimal working point was selected such that it will be at least $2{ }^{\circ} \mathrm{C}$ above the crystalization boundary. Working conditions to be avoided are marked in black.

\section{Detailed account of parasitic losses estimation}

The work of the air blower was estimated based on several commercially available similar blowers. The work of the pumps was calculated by Eq. 1S based on the fluid volumetric flow rate and assuming pressure loses in the pipes as detailed in Table $2 \mathrm{~S}$,

$$
P_{r p}=\dot{V} \Delta p / \eta
$$

where $P_{r p}[\mathrm{~kW}]$ is the power requirement of the pump, $\dot{V}\left[\mathrm{~m}^{3} / \mathrm{s}\right]$ is the volumetric flow rate, $\Delta p$ $[\mathrm{kPa}]$ is the total pressure difference that the pump needs to supply and $\eta[-]$ is the pump efficiency. The power requirement of the vacuum pump depends on its displacement rate $\dot{N}_{v p}$ and is calculated for an isentropic compressor that transports gaseous compounds from a low pressure environment, $p_{1}$, to a higher pressure (atmospheric pressure) environment, $p_{2},{ }^{1 \mathrm{~S}}$

$$
P_{v p}=\frac{1}{\eta_{s}} \frac{\gamma R T}{\gamma-1}\left[\left(\frac{p_{2}}{p_{1}}\right)^{\frac{\gamma-1}{\gamma}}-1\right] \dot{N}_{v p}
$$

where $P_{v p}[\mathrm{~kW}]$ is the power requirement of the vacuum pump, $\gamma$ is the ratio of the air constantpressure to constant-volume specific heats $(\gamma=1.4[-]), R$ is the universal gas constant $(8.314$ 
$[\mathrm{J} / \mathrm{mol} \mathrm{K}])$ and $T[\mathrm{~K}]$ is the ambient temperature. An isentropic efficiency of $\eta_{s}=0.5$ was assumed. The lower pressure, $p_{1}$, was assumed to be $1 \mathrm{kPa}$ higher than the saturation pressure of the water vapor at the condenser temperature. The gas displacement of the vacuum pump compensates for the presence of non-condensable gases in the condenser. These gases are either released from the liquid desiccant during its heating in the desorber, or leaking into the subpressurized system components.

Table 2S. Estimated breakdown of the parasitic losses.

\begin{tabular}{|c|c|}
\hline Component & Power (W) \\
\hline Blower & 580 \\
\hline Absorber circulation pump ${ }^{2 \mathrm{~S}}$ & 180 \\
\hline Desorber circulation Pump & 25 \\
\hline Hot water pump & 180 \\
\hline Cold water pump & 180 \\
\hline Solar collectors circulation & \\
\hline pump $^{2 S}$ & 50 \\
\hline Vacuum pump & 30 \\
\hline
\end{tabular}

Figure $2 \mathrm{~S}$ depicts the increase in energy requirements (relative to the baseline requirements) when the parasitic losses are increased by $50 \%(1.88 \mathrm{~kW})$ compared to the best estimates of the parasitic losses (Table 2S). This calculation represents a conservative scenario. The results are normalized to the energy requirements per unit water production $(\mathrm{kWh} / \mathrm{l})$. 


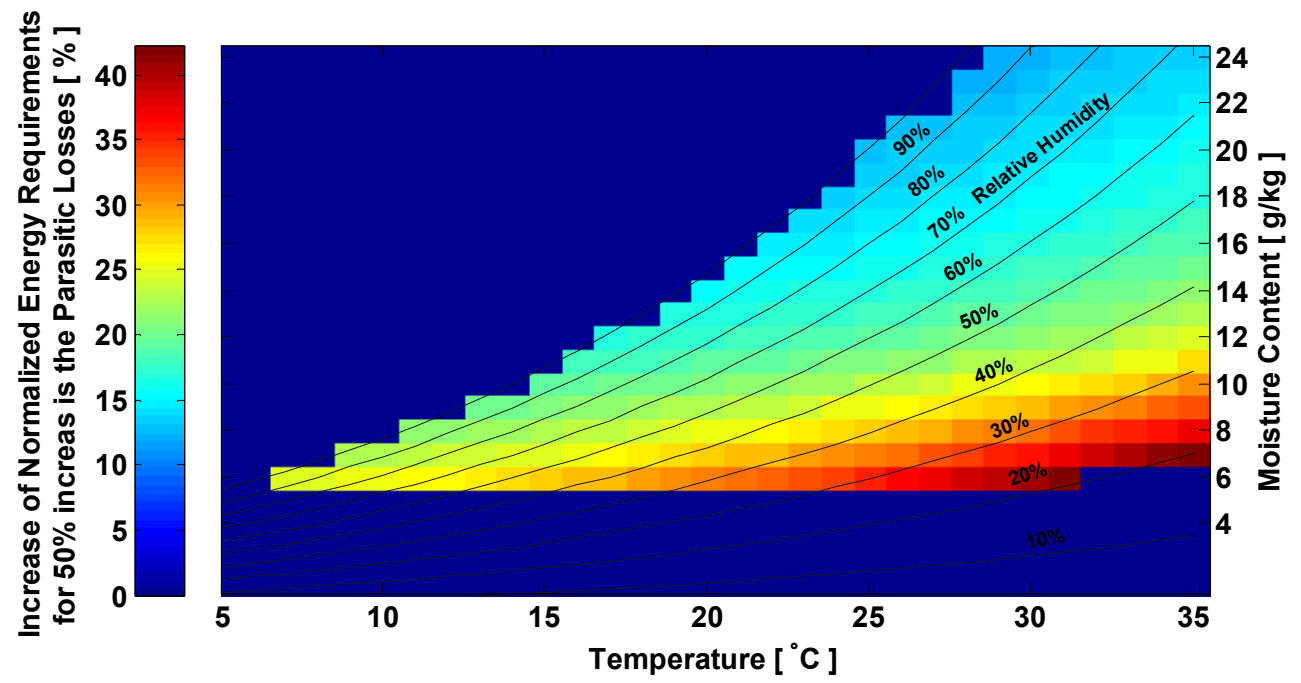

Figure 2S. Relative normalized energy requirement due to a conservative estimation of the fixed parasitic loses (50\% above the baseline estimation). The baseline normalized energy requirement are based on the parasitic losses detialed in Table $2 \mathrm{~S}$.

\section{References}

${ }^{1 S}$ Beysens, D.; Broggini, F.; Milimouk-melnytchouk, I.; Ouazzani, J.; Tixier, N. New Architectural Forms to Enhance Dew Collection. Chem. Eng. Trans. 2013, 34, 79-84.

${ }^{2 \mathrm{~S}}$ Sharan, G. Harvesting dew with radiation cooled condensers to supplement drinking water supply in semi-arid coastal northwest India. Int. J. Serv. Learn. Eng. 2002, 6 (1), 130-150. 